\title{
Commentary: My patients heart needs surgery, but the rest of his body... not so sure: Operative indications and options in frail patients
}

\author{
Michel Carrier, MD, MBA, and Yoan Lamarche, MD \\ From the Department of Cardiac Surgery, Montreal Heart Institute, Université de Montréal, Montreal, Quebec, \\ Canada. \\ Disclosures: Authors have nothing to disclose with regard to commercial support. \\ Received for publication Sept 17, 2018; accepted for publication Sept 18, 2018; available ahead of print Nov 17, \\ 2018. \\ Address for reprints: Michel Carrier, MD, MBA, Montreal Heart Institute, 5000 Belanger St, Montreal, Quebec \\ H1T 1C8, Canada (E-mail: michel.carrier@icm-mhi.org). \\ J Thorac Cardiovasc Surg 2019;157:1910-1 \\ $0022-5223 / \$ 36.00$ \\ Copyright $(c) 2018$ by The American Association for Thoracic Surgery \\ https://doi.org/10.1016/j.jtcvs.2018.09.092
}

There is no doubt in our minds, typical cardiac surgery patients have gone from middle-aged men needing isolated coronary artery bypass grafting to elderly multiorgan dysfunction patients with heart failure who need complex coronary artery bypass grafting and valvular surgery. The main question remains, should we operate on the elderly and "eyeballed" frail patients. How can we ensure minimal operative mortality and complications with the best chances of midterm recovery and good quality of life, maintaining patient autonomy?

There is no easy answer to the question. In this issue of The Journal of Thoracic and Cardiovascular Surgery Yanagawa and colleagues ${ }^{1}$ review currently available assessment tools, ongoing studies on training of frail preoperative patients, and discuss potential effects of frailty on resource use and allocation. They report available approaches to determine the presence of frailty, defined as a form of vulnerability to stress due to loss of physiologic reserve. In their discussion, the stressor represents the surgical technique itself and the syndrome is most often seen as patient exhaustion, malnutrition, wasting, weakness, slowness, and inactivity, which most often characterize the very elderly patients and those with advanced heart failure.

Identification of frailty is only the first step; what to do next? Can frail patients be better prepared to undergo surgery? Can mortality and overall results of surgery be improved such as to qualify the recovered frail patients for such interventions? Again, there is no easy answer, but the authors describe 2 ongoing clinical studies, the Pre-operative REhabilitation for reduction of Hospitalization After coronary Bypass and valvular surgery (PREHAB) and the Protein and Exercise to Reverse Frailty in OldeR Men and women undergoing Transcatheter Aortic Valve Replacement (PERFORM TAVR) trials. Both are investigating exercise, education, and nutritional supplements to attempt to de-

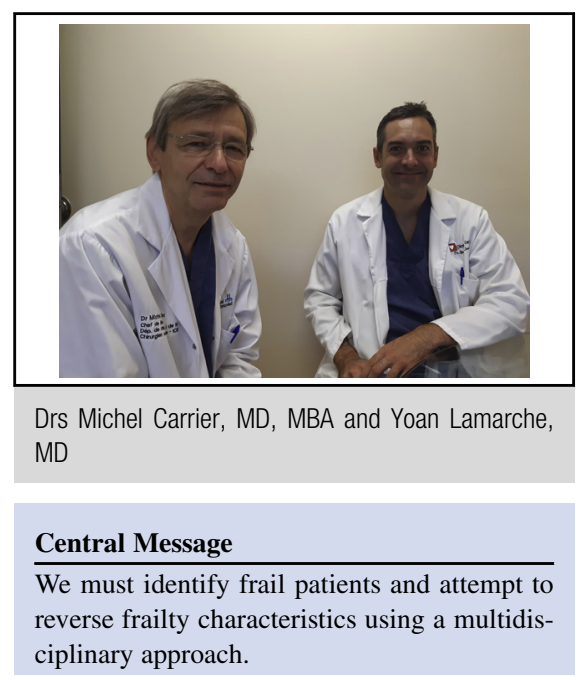

See Article page 1905. frail these patients after identification but before any elective interventions with the hope to improve survival, quality of life, and need for hospital readmission.

The authors suggest that there is convincing evidence to support the fact that frailty is a significant risk factor and a marker of poor outcomes after surgery. They also suggest that meanwhile, our approach to the frail patient should be designed with the help of an interdisciplinary team including a geriatric specialist, physiotherapist, nutritionist, and a social worker. The objective is to identify frail patients, to correct reversible frailty characteristics preoperatively, and to help postoperative care of these patients.

The underlined message is also that the days when a patient and his family are seen by a single surgeon in his office are gone. For the benefit of all of our patients, especially the elderly and the advanced heart failure ones, shouldn't we all work in multidisciplinary teams in which all aspects of patient care, preoperative, operative, and postoperative are discussed and shared. This should lead to better informed consent, better prepared patients, and the best possible outcomes if surgery is chosen. The questions that remain are: can a patient who is correctly identified as frail be de-frailed using a prehab program? If the program succeeds, will it lead to better outcomes? If it fails, should the patient receive an operation anyway? 
Hopefully, ongoing studies will partially answer those questions and clarify how resource use should be optimized in the care of these difficult patients.

\section{Reference}

1. Yanagawa B, Graham MM, Afilalo J, Hassan A, Arora RC. Frailty as a risk pre dictor in cardiac surgery: beyond the eyeball test. J Thorac Cardiovasc Surg. 2019;157:1905-9. 